\title{
Effects of Fertility Trends on Population Aging in Finland
}

\author{
WOLFGANG LUTZ
}

Research Scholar

International Institute for Applied Systems Analysis

Laxenburg, Austria

Population aging is considered to be a difficult if not the most serious demographic problem for industrialized societies. The word aging usually characterizes the process of changes in a population's age distribution which gives more weight to older agegroups and increases the mean age of the population. The consequences of aging are manifold. They range from social security issues and the question of health care for the elderly to labor supply and the demand for certain goods in the economy, even cultural values and attitudes towards innovation and change might alter if people under age 35 become a decreasing minority.

Aside from these macro level consequences every individual will experience the effects of population aging in his own life: Increasing life expectancy together with the smaller number of children per mother or father will further increase the time and the intensity of care younger men and women are expected to give to their elderly parents. Furthermore the negative consequences of being a member of a large birth cohort (see Easterlin, 1980) such as that of the baby boom will be reinforced by the process of aging. As we can see it now the cohorts born in the late 1940s in Finland will be the largest age-group in the population not only in their youth but up to age 70 or even beyond. This means higher competition not only for the universities and on the job market but also for senior citizens' homes, and social security benefits for which a decreasing number of people must pay.

Although the consequences of aging are very complex its determinants are easy to list: decreasing mortality, decreasing fertility, and possibly some migration effects. This paper will focus on the demographic determinants of population aging and especially on the effects of changing fertility patterns on the dramatic changes of the age structure that we can already observe and can expect for the future.

\section{Changing age structures $1751-2025$}

The long history of population records in Finland allows us to view the phenomenon of aging with a long-term perspective. Registered data on the population age structure start in 1751 when the Swedish-Finnish system of population statistics was introduced. From that year we have uninterrupted time series up to present. Combined with the United Nations (1985) estimates we can base our analysis on a series which extends to the year 2025. In this paper we will attempt a mainly visual analysis of the changing age structure over these 275 years of Finnish history.

Figure 1 presents a three-dimensional picture of changes in the female age distribution over time. Age-groups run from left to right with girls aged $0-4$ at the left end and women aged 80 and above at the center. Time runs from right to left with 1750 at the far right end and the more recent years at the center. The time series has been cut into three pieces to get a clearer view of the age profile. Hence, the angle of observation is such that we look back into history from a point somewhere in the future. The gridding refers to five-year age groups and five-year periods. 
F i g u r e 1. Changes in the female age distribution, Finland 1751-2025.

Figure $1 \mathrm{a}$.

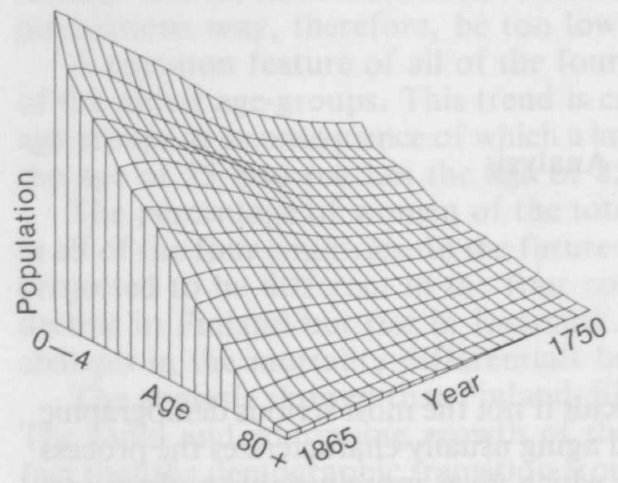

Figure $1 \mathrm{~b}$.

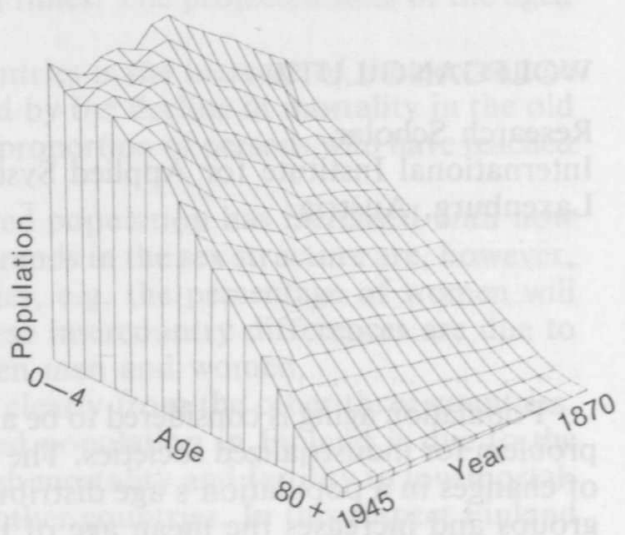

Figure $1 \mathrm{c}$.

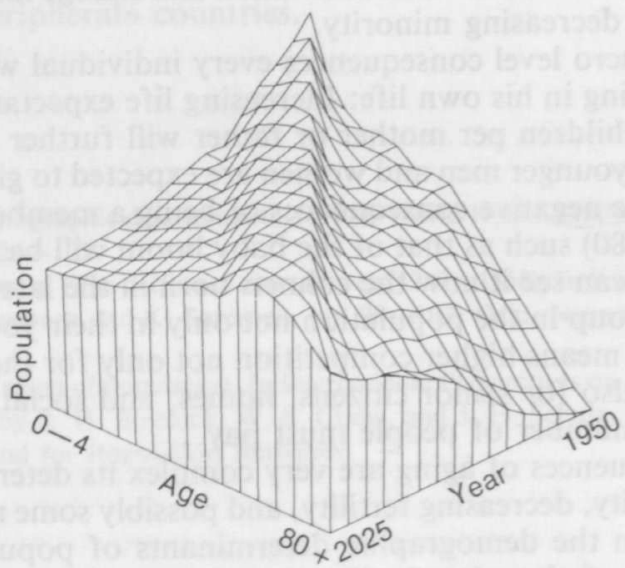

The first part of Figure 1 a covering the period from 1750 to 1865 gives the typical age structure for a premodern society with very high proportions of young people. The slope of the age profile is steep and almost linear. It is because of this shape that demographers speak of population "pyramids" (when the male age distribution is put beside it). The slope is steepest for the first five years of age because this used to be the years of highest mortality. Despite the almost identical patterns in 1750 and 1865 we see that the Finnish population had substantially grown in size over that period, especially since the beginning of the 19th century. Hence the steepness of the slope with respect to age in 1865 is partly due to the high speed of population growth at that time. To obtain an age profile produced exclusively by mortality (and possibly migration) we would have to cut along the diagonals. This would result in a picture of cohort survivorship.

The premodern pattern essentially continued until 1910 when fertility entered its secular decline. For cohorts born before 1910 the age gradient (even in 1945) remained as before. For those born after 1910 an edge of the pyramid seems to have been cut away. In the following analysis of fertility trends we will shed further light on the determinants of this unprecedented change in the population's age structure. Another 
interesting feature in Figure $1 \mathrm{~b}$ is the notch that runs across the graph starting with the cohort born around 1870 and running over all ages up to those aged 75 in 1945 . This notch seems to be a consequence of the severe mortality crisis in 1868 when, because of a great famine, mortality was extraordinarily high at all ages but especially for young children. Also fertility was very low around these years. As a consequence at all years up to 1945 this notch also means a change in the slope of the age profile. It also looks similar to the demographic discontinuity Keyfitz (1986) observed for the less developed world around the middle of the 20 th century.

The age profiles for the period 1950 to 2025 (Figure 1 c) deviate completely from the traditional pyramidal form. The picture is dominated by one big ridge that starts at age $0-4$ in 1950 and continues to the end of our observation period. This ridge represents the large cohorts born during the so-called post World War II baby boom. The demographic impact of that high fertility period has been so great that it determines the age distribution well into the 21 st century. Part of the reason for this immense age-structural effect of the baby boom is also the low level of mortality experienced by those very large birth cohorts. As a consequence of this development, today there are more women aged 35-39 than in any other age-group and even in the year 2025 the largest age-groups will be those between 55 and 74. Another indication of the significant improvements in mortality conditions is the steep increase in the number of women aged 80 and above.

\section{Age-specific growth rates $1830-1985$}

A more detailed analysis of age-distributional changes can be conducted by looking at age- and period-specific rates of change instead of absolute numbers. Figure 2 depicts the pattern of age-specific growth rates over the period $1830-1985$. Using the same input data on age distributions as for Figure 1 ratios were calculated by

F i g u r e 2. Age-specific growth rates: female population, Finland 1830-1985.

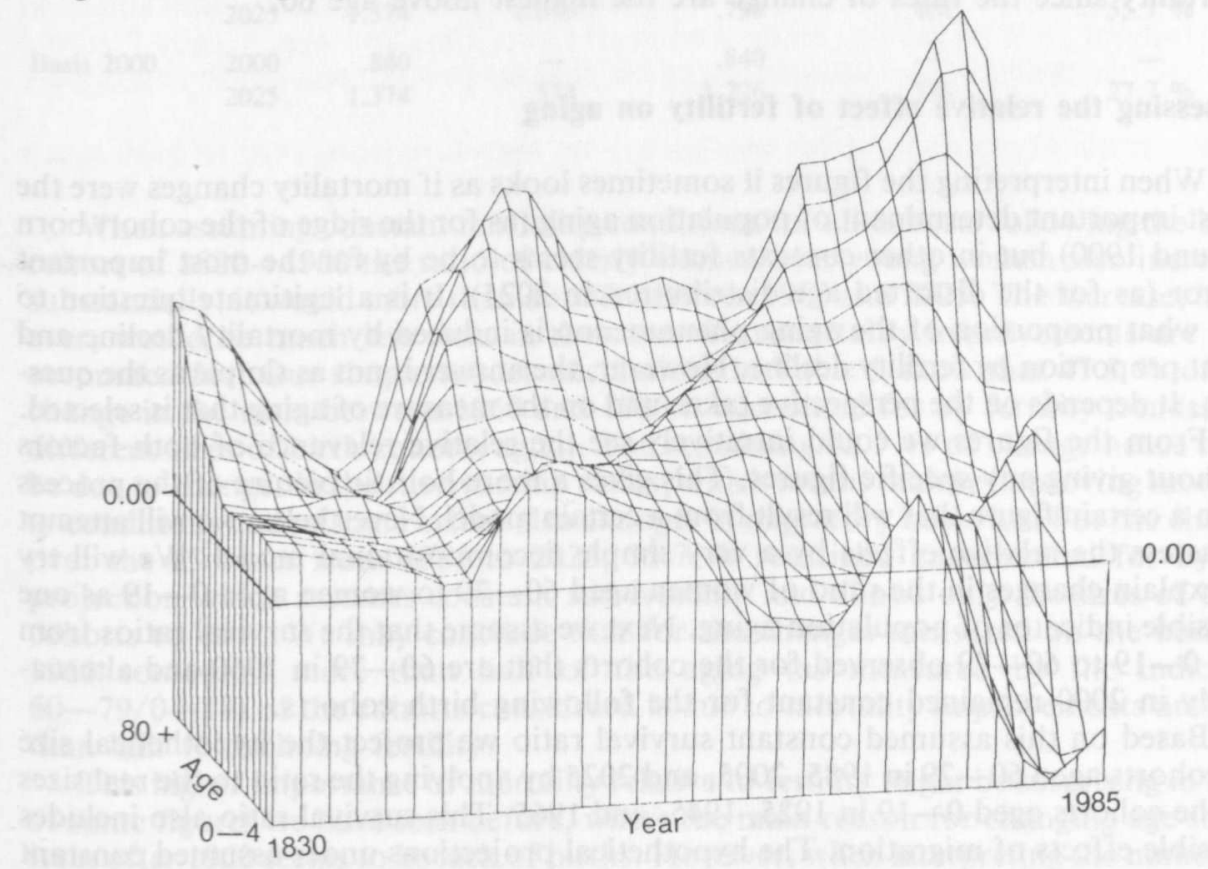

Age-specific growth rates - Finland 1830-1985 
dividing the population in a certain age-group and a given year by the population figure of the same age group 5 years before and subtracting 1 .

The surface of Figure 2 has been smoothed slightly to make it easier to recognize major trends. The still scattered picture of mountains indicates the instability of agespecific growth rates over the last 150 years in Finland. Again diagonal ridges indicate cohort effects and vertical notches negative period influences. Until the great famine in 1868 the population grew in all age-groups, even somewhat stronger at ages above 60 than below. The great famine is clearly visible as a notch across all ages which effected most severe the age-groups $0-4$. The unsmoothed data show very high negative growth rates for the year 1869 . After 1870 mortality conditions improved at all ages leading to positive growth rates in all age-groups. The improvements were highest for child mortality but also for women already grown up in 1869 . An increase in the height of the ridge appearing over time indicates improving mortality conditions at more advanced ages.

The deficit of births from the time of the great famine is also visible along the cohort line. At all ages this is followed by a steep increase in age-specific growth rates. Between the small cohorts of the famine years and the onset of the modern fertility decline around 1910 birth rates were high and survivorship relatively favorable thus resulting in a major ridge that is the most dominant feature of Figure 2 . For the cohorts born after 1910 a dramatic decrease in age-specific growth rates is the consequence of declining fertility. The thin and steep ridge to the very right of the graph is the result of the post World War II baby boom. After that growth rates at young age-groups decline to the lowest level in Finnish history aside from individual years of catastrophe.

It is interesting to notice that the increase over time seems to be less for the baby boom ridge than for the cohorts born before 1910. The cohort born around 1900 at age 85 shows the greatest age-specific growth rate ever observed in Finnish history. Since the increase is much less pronounced during the younger ages of the cohort this must be due to dramatic mortality improvements relative to the previous cohorts. It seems that this cohort experienced the greatest improvements in mortality conditions in modern history. And these changes were most pronounced for old age mortality since the rates of change are the highest above age 60 .

\section{Assessing the relative effect of fertility on aging}

When interpreting the figures it sometimes looks as if mortality changes were the most important determinant of population aging (as for the ridge of the cohort born around 1900) but in other contexts fertility seems to be by far the most important factor (as for the distorted age distribution in 2025). It is a legitimate question to ask what proportion of the aging phenomenon is induced by mortality decline and what proportion by fertility decline. However, the answer is not as simple as the question. It depends on the perspective taken and on the measure of aging that is selected.

From the figures we could intuitively see the relative relevance of both factors without giving any specific figures. This gives a more holistic picture of the process than a certain figure that will result from a certain model. Nevertheless we will attempt to assess the relative effects by a very simple decompositional model. We will try to explain changes in the ratio of women aged $60-79$ to women aged $0-19$ as one possible indicator of population aging. Next we assume that the survival ratios from age $0-19$ to $60-79$ observed for the cohorts that are $60-79$ in 1960 and alternatively in 2000 remained constant for the following birth cohorts,

Based on this assumed constant survival ratio we project the hypothetical size of cohorts aged $60-79$ in 1985,2005 , and 2025 by applying the ratio to the real sizes of the cohorts aged $0-19$ in 1925,1945 , and 1965 . This survival ratio also includes possible effects of migration. The hypothetical projections under assumed constant cohort mortality conditions are then related to the real figures (for 1985) or to the 
real projections incorporating both changing fertility and mortality conditions. The aging indicator based on the hypothetical projections is in all cases less than that based on real data. The difference is due to the fact that the hypothetical indicator only covers changes induced by changing sizes of birth cohorts whereas the indicator based on real data also includes mortality improvements and hence a higher extent of aging.

Aging is a process and not a status and for this reason we want to interpret the change in the ratio $60-79 / 0-19$ and not its absolute level. The empirical ratio which is based on changes in both mortality and fertility more than doubled over the 25 years from 1960 to 1985 . It is expected to increase to more than four times its 1960 size by the year 2025 . While in 1960 more than three young women aged $0-19$ existed per one elderly woman aged 60-79 in 2025 there will be significantly more women aged $60-79$ than women aged $0-19$. These dramatic changes will be discussed in more detail below.

$\mathrm{T}$ a b 1 e 1. Decomposition of aging into fertility and mortality components.

Basis 1960 Survival ratio from the age group 0-19 in 1900 to age group 60-79 in 1960: .464 Basis 2000 Survival ratio from age group 0-19 in 1940 to age group 60-79 in 2000: .715

Ratio of women aged $60-79$ to women aged $0-19$

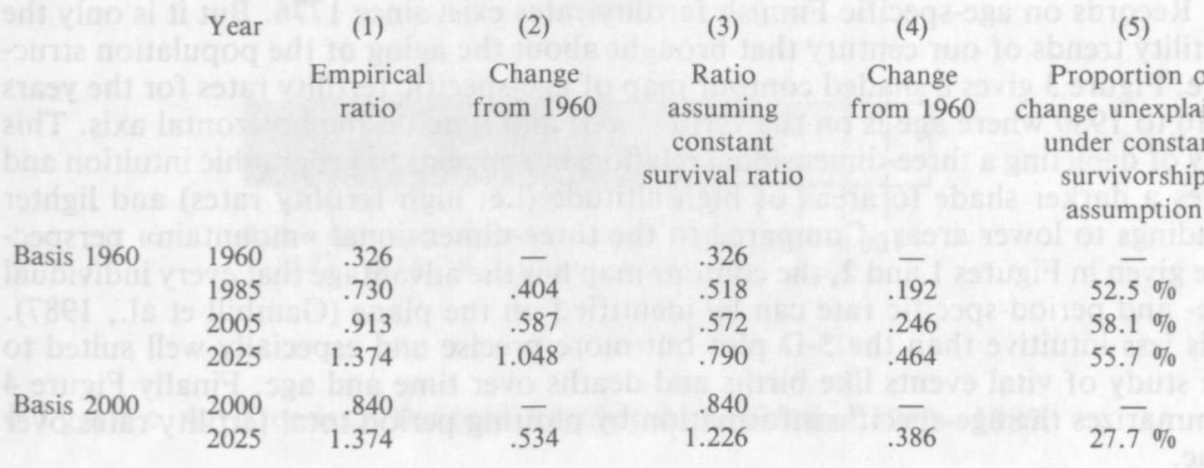

When assuming constant mortality conditions for all cohorts following the birth cohort of 1880-1900 the ratio of elderly women over young women also increases substantially: it would more than double between 1960 and 2025 . The increase, however, would be much less than in the case when mortality improvements are also accounted for. Our simple model calculations in Table 1 show that $47.5 \%$ of the change in the ratio between 1960 and 1985 is accounted for by fertility trends, i.e. different sizes of birth cohorts aging. The remaining $52.5 \%$ of change hence must be due to changes in the survivorship ratios, which means mainly improving mortality conditions and to some extent also changes in migratory behavior. For the change over the 65 years from 1960 to $2025,55.7 \%$ remained unaccounted for by the projection which assumes constant survivorship and allows only the sizes of birth cohorts to vary. We may conclude that for the changes measured on the basis of 1960 somewhat more than half of the aging (as measured by the indicator $60-79 / 0-19)$ of the cohorts considered is due to mortality improvements and less than half to declining fertility.

This higher importance of mortality relative to fertility might be surprising in light of some figures we have seen before, where the main reason for changing age structures after 1960 seems to be lack of births. However, when interpreting the numerical results given in Table 1 we have to keep in mind that the survivorship ratios consid- 
ered reflect mortality conditions going back to the beginning of our century. The birth cohort of $1880-1900$ was still exposed to very high mortality conditions and we have to recognize that a survivorship ratio of .464 , i.e. a situation where less than half of the women aged $0-19$ will reach age $60-79$, is very low by modern standards. The period life table of 1983 gives for women a probability of .820 of surviving from age 10 to 70 . Hence in a situation with less dramatic mortality changes for the older cohorts aging is expected to depend more heavily on fertility trends. This is clearly shown by the model calculated on the basis of the year 2000 . For the very dramatic increase in population aging between 2000 and 2025 only $27.7 \%$ of the projected change may be attributed to assumed future mortality improvements and $72.3 \%$ are the effect of low fertility levels. This confirms our prima facie graphical analysis for the 21 st century.

Different models of decomposition yield different results. The key questions are: »Do the age-groups considered in a given year include the large cohorts of the baby boom?» and »What mortality level does the model refer to?». Generally the graphical representation tells more than many different models because it contains all aspects at once and appeals to intuition. Model calculations like the ones given above may, however, help to make our point more precise and more defensible.

\section{Underlying fertility trends}

Records on age-specific Finnish fertility rates exist since 1776. But it is only the fertility trends of our century that brought about the aging of the population structure. Figure 3 gives a shaded contour map of age-specific fertility rates for the years 1910 to 1980 where age is on the vertical axis and time on the horizontal axis. This way of depicting a three-dimensional relationship appeals to geographic intuition and gives a darker shade to areas of high altitude (i.e. high fertility rates) and lighter shadings to lower areas. Compared to the three-dimensional »mountain» perspective given in Figures 1 and 2, the contour map has the advantage that every individual age- and period-specific rate can be identified on the plane (Gambill et al., 1987). It is less intuitive than the 3-D plot but more precise and especially well suited to the study of vital events like births and deaths over time and age. Finally Figure 4 summarizes the age-specific information by plotting period total fertility rates over time.

From the above pictures we see that the twenty years from 1910 to 1930 saw a very steep decline of fertility at all ages. This is what demographers usually call the great fertility transition from a pattern of traditionally high and virtually uncontrolled fertility to modern low fertility levels. In Finland this secular fertility decline started on a national level around 1910 . Until 1933 the total fertility rate went down to less than half of its 1910 value. Despite later increases in fertility this transition can be regarded as an irreversible change in reproductive behavior. Time series of the sindex of family limitation» calculated elsewhere (Lutz, 1984) also indicate that fertility was essentially natural before 1910 and that famility limitation was introduced around that time.

The monotonic fertility decline at the beginning of the century is interrupted only by World War I and the Finnish Civil War. In 1919 fertility at all age-groups was far below the trend, followed by a recovery in $1920-21$. We also see that fertility for women above age 30 declined fastest whereas teenage fertility showed no significant change. For women in their twenties we also see some cohort effects (diagonal lines) on the contour map: Women in earlier cohorts did not reduce their fertility up to the late twenties whereas younger cohorts already started out with lower fertility levels at younger ages.

Around 1933 fertility in Finland, as in most industrialized countries, reached a local minimum. The total fertility rate was down to a level of 2.2. From the contour map we see that during that period also younger women in their lower twenties re- 
F i g u r e 3. Contour map of age-specific fertility rates, Finland 1910-1980.
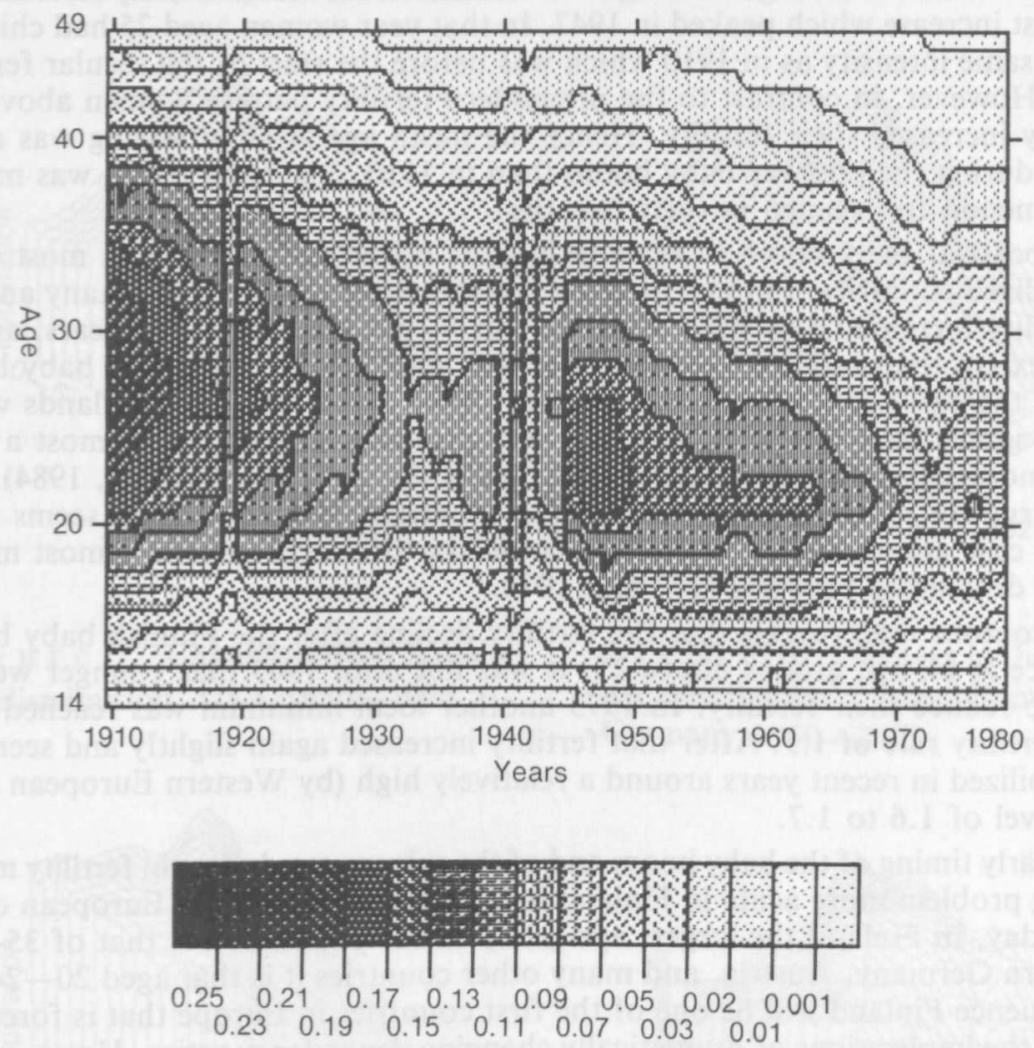

F i g u r e 4. Trends in the total fertility rate, Finland 1910-1980.

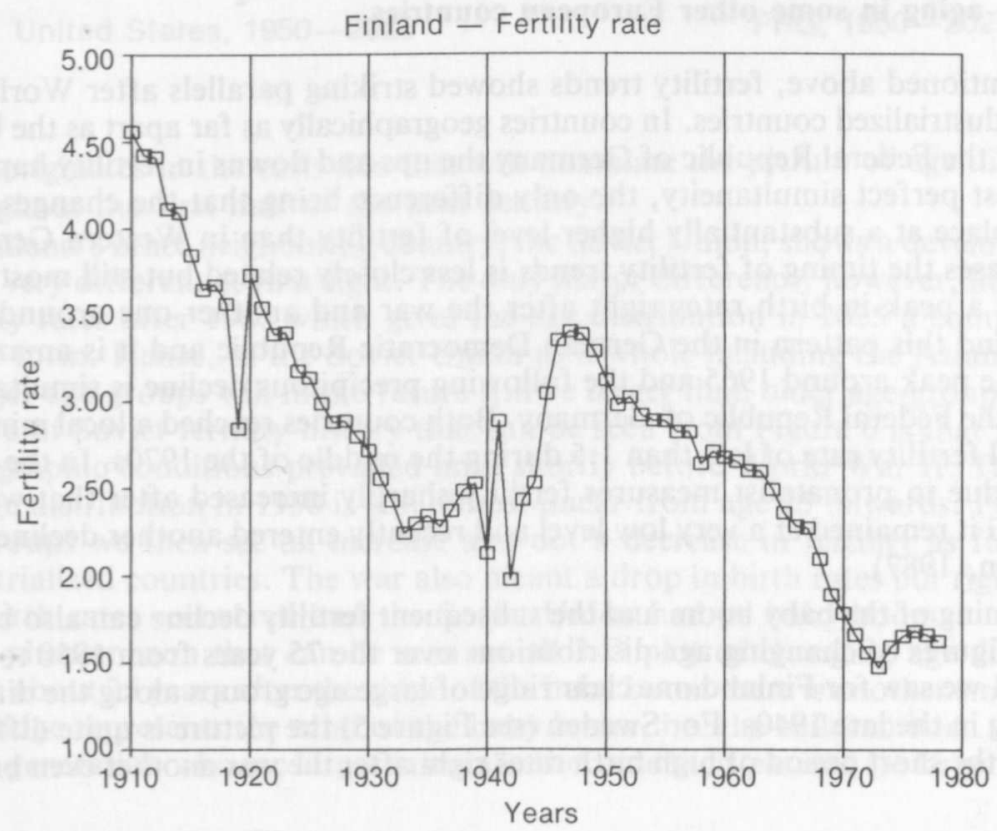


duced their fertility. This was followed by a series of fast ups and downs during the course of World War II. Right after the war had ended in Finland fertility rates entered a very fast increase which peaked in 1947. In that year women aged 25 had children with the same intensity as in 1910 which was before the start of the secular fertility decline. However, in contrast to the premodern fertility pattern women above age 30 hardly increased their fertility. Hence the mean age at childbearing was much younger during the postwar baby boom than in 1910. The baby boom was mainly a phenomenon for women in their twenties.

The postwar baby boom in Finland is quite different from that in most other industrialized countries. In most of those countries (e.g. Western Germany and the US) fertility increased also right after the war - but only for a few years, and to a lesser extent than in Finland - and declined again to show the real baby boom not until the early 1960s (Lutz and Yashin, 1987). Even in the Netherlands where the peak immediately after the war was very pronounced (reaching almost a TFR of 4.0) another local maximum appeared during the early 1960s (Festy, 1984). The same is true for all the other Scandinavian countries. Hence, Finland seems to be a unique case among the industrialized countries with fertility rates almost monotonically decreasing between 1947 and 1974 .

The contour map reveals that the fertility decline after the Finnish baby boom took place at all age groups above 25 . It was not until 1965 that younger women started to reduce their fertility. In 1973 another local minimum was reached with a total fertility rate of 1.5. After that fertility increased again slightly and seems to have stabilized in recent years around a relatively high (by Western European standards) level of 1.6 to 1.7 .

The early timing of the baby boom and of the subsequent decline in fertility makes the aging problem more acute in Finland today than in most other European countries. Today, in Finland the largest age-group in the population is that of $35-39$. In Western Germany, Austria, and many other countries it is that aged $20-24$. As a consequence Finland will be one of the first countries in Europe that is forced to adjust to the implications of dramatically changing dependency ratios. However, the relatively high level of current fertility will help to dampen the effect somewhat as compared to other countries.

\section{A view to aging in some other European countries}

As mentioned above, fertility trends showed striking parallels after World War II in all industrialized countries. In countries geographically as far apart as the United States and the Federal Republic of Germany the ups and downs in fertility happened with almost perfect simultaneity, the only difference being that the changes in the US took place at a substantially higher level of fertility than in Western Germany. In other cases the timing of fertility trends is less closely related but still most countries show a peak in birth rates right after the war and another one around 1962. We also find this pattern in the German Democratic Republic and it is amazing to see that the peak around 1965 and the following precipitous decline is simultaneous to that in the Federal Republic of Germany. Both countries reached a local minimum in the total fertility rate of less than 1.5 during the middle of the $1970 \mathrm{~s}$. In the GDR, however, due to pronatalist measures fertility sharply increased after that whereas in the FRG it remained at a very low level and recently entered another decline (Lutz and Yashin, 1987).

The timing of the baby boom and the subsequent fertility decline can also be read from the figures of changing age distributions over the 75 years from 1950 to 2025 . In Figure 1 we saw for Finland one clear ridge of large age groups along the diagonal originating in the late 1940s. For Sweden (see Figure 5) the picture is quite different: Following the short period of high birth rates right after the war another even broader 
$\mathrm{F}$ i g u r e 5. Changes in the female age distribution, Sweden 1950-2025.

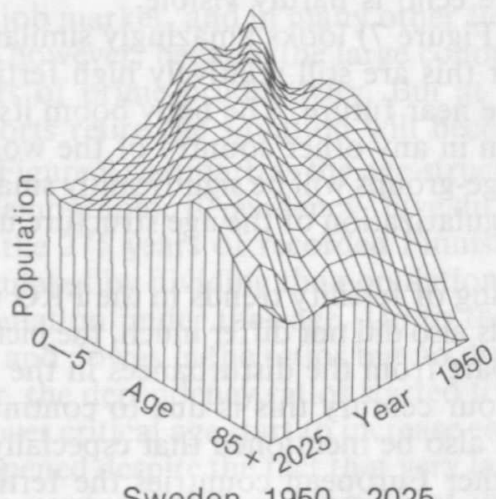

Sweden, $1950-2025$

$\mathrm{Fig} \mathrm{u} \mathrm{re} \mathrm{7.} \mathrm{Changes} \mathrm{in} \mathrm{the} \mathrm{female}$ age distribution, USA 1950-2025.

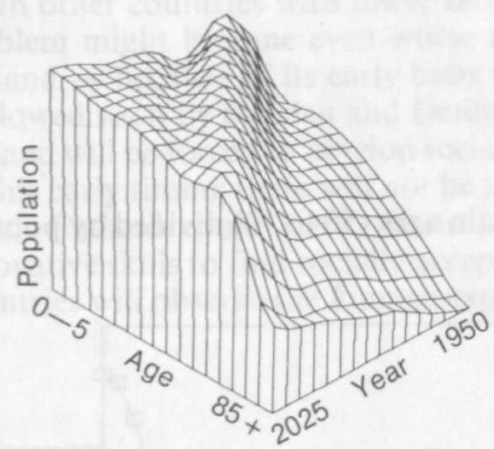

United States, 1950-2025
$\mathrm{F}$ i g u r e 6. Changes in the female age distribution, USSR 1950-2025.

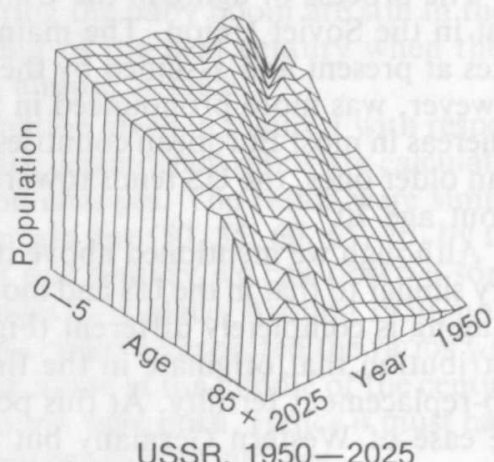

F i g u r e 8. Changes in the female age distribution, Federal Republic of Germany $1950-2025$.

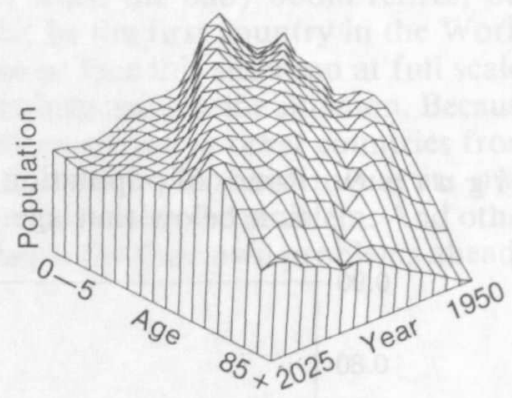

FRG, 1950-2025

ridge originates in the early 60 s that will dominate the picture of age distributions throughout the first half of the next century.

Finland's other neighboring country, the Soviet Union, shows a development that looks very different at first sight. The only major difference, however, lies in higher fertility rates after 1960 which gives the age distribution in 2025 a completely different form. Hence, in the Soviet Union as a whole including the Asian Republics younger age-groups will in the future still be larger than older age-groups. Another feature of Soviet fertility history that can be seen from Figure 6 is that premodern demographic conditions prevailed until shortly before World War II. The slope of the age distribution in 1950 is still almost linear from age 25 onwards. For younger age-groups we then see an increase and not a decrease in fertility as for all other industrialized countries. The war also meant a drop in birth rates but right after the war birth rates recovered and the Soviet Union had its baby boom.

A phenomenon that can be seen on all 3-D plot of changing age distributions is that about 25 years after the ridge of the baby boom there is another smaller ridge. This ridge represents the echo of the baby boom, i.e. the children born to the baby boom generation who are larger in number because their parents are larger in number 
even at constant or slightly declining fertility rates. Only in countries where the baby boom was not very concentrated and fertility declined strongly during the period when we would expect an echo (like in Sweden), the echo is hardly visible.

The process of aging in the United States (Figure 7) looks amazingly similar to that in the Soviet Union. The main reason for this are still relatively high fertility rates at present and assumed by the UN for the near future. The baby boom itself, however, was more pronounced in the US than in any other country of the world. Whereas in most European countries younger age-groups will be significantly smaller than older ones, the US tends towards a rectangularization of the age structure until about age 70 .

Although we mentioned above that the timing of fertility trends in the FRG was very similar to that in the US and mortality trends also did not differ much, the picture of aging is completely different (Figure 8). Apart from the disturbances in the age distribution that originate in the first half of our century this is due to continued sub-replacement fertility. At this point it must also be mentioned that especially in the case of Western Germany but also for other European countries the fertility assumptions made by the UN (1985) seem much too high. The UN assumes substantial increases in total fertility: by the year 2025 it is assumed to reach a level of more than 2 children per woman. In reality, however, fertility in the FRG shows a further declining trend and there is no immediate reason to expect a reversal of this trend. If Figure 9 would have been based on more realistic projections the age distributional changes would look even much more dramatic.

F i g u r e 9. Ratios of population above certain ages ( 50 to 70 ) divided by population below that age.

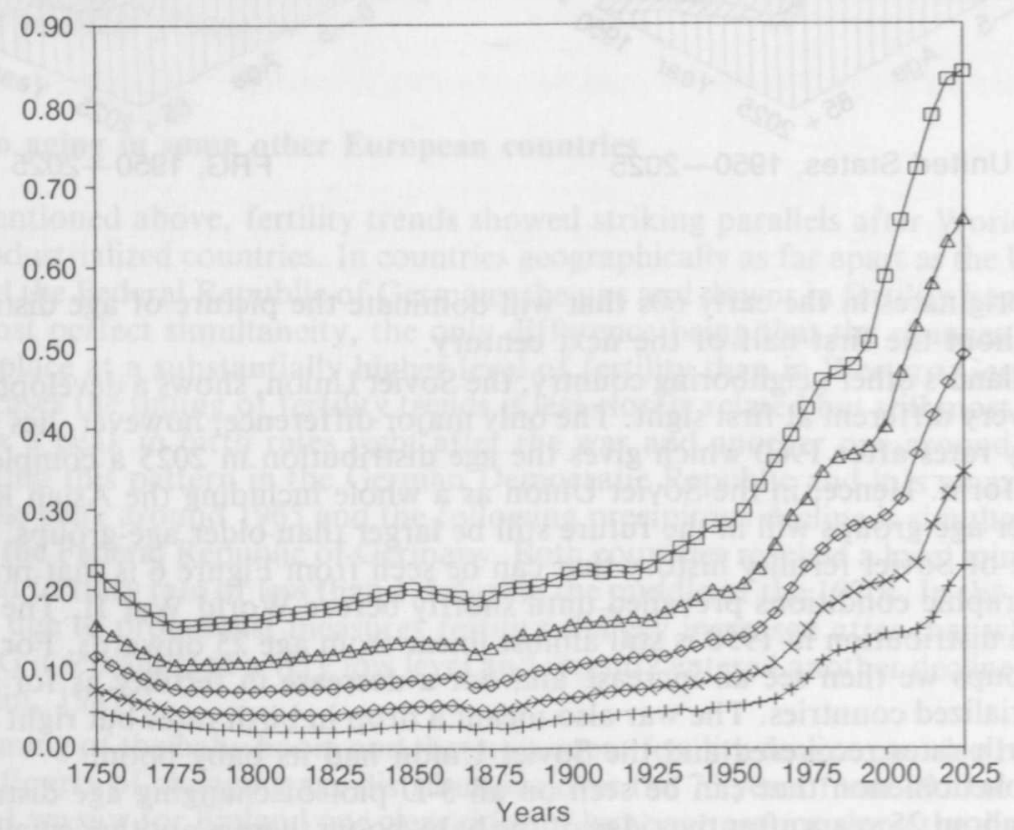

$\square$ Rate: $\frac{50+}{0-49} \triangle$ Rate: $\frac{55+}{0-54} \diamond$ Rate: $\frac{60+}{0-59} \times$ Rate: $\frac{65+}{0-64}+$ Rate $\frac{70+}{0-69}$ 


\section{Discussion}

Some of the effects of aging are already being felt in the educational system, on the job market, and in many other fields. Economically the situation is not yet critical, however, because the large cohorts born during the baby boom are still in their years of prime productivity. But at the beginning of the next century when these cohorts retire the situation will become critical almost at once.

Figure 9 summarizes the age-structural information given in Figure 1 with respect to demographic dependency. Five different old age dependency ratios are calculated for the 275 years of recorded Finnish population changes. The ratios were simply calculated by dividing the population above a certain age $(50,55,60,65,70)$ by the population under that age. Up to the middle of our century we can observe some ups and downs in the ratios but no dramatic changes took place. Around 1950, however, the dependency ratios started to take off. As could be expected the ratios with a lower critical age start to increase earlier. This increase at the middle of the century happened despite the fact that very large new cohorts were born. Hence it must have been predominately a function of improving survivorship to old age.

The process of steadily increasing dependency ratios seems to go on until the turn of the century when the large cohorts of the baby boom cross the critical age of our ratios. After that point dependency ratios explode to levels five times greater than those experienced through centuries up to World War II. At least at this point many parts of our social system will come under extreme stress and the "pension gap» will widen enormously.

In other countries with lower fertility currently than Finland (like the FRG) the problem might become even worse at the point when the baby boom retires, but Finland - because of its early baby boom - will be the first country in the World (followed soon by Sweden and Denmark) to have to face this situation at full scale. Finland will be forced to develop social models that help manage the situation. Because of this early timing there will not be many models employed in other countries from which Finland could learn. Hence, the Finnish society will have to use its own innovative skills to find socially acceptable ways to cope with the problem. And other countries will observe the Finnish experience to learn for their own problems ahead.

\section{References}

Easterlin, R. (1980). Birth and Fortune. The Impact of Numbers on Personal Welfare. New York: Basic Books.

Festy, P. (1984). Fertility in Western Countries from 1870 to 1970. Population Studies Translation Series, No. 7. Bangkok: United Nations.

Gambill, B.; Vaupel, J.; and Yashin, A. (1986). Thousands of Data at a Glance: Contour Maps in Demography. RR-86-6. Laxenburg, Austria: International Institute for Applied Systems Analysis,

Keyfitz, N. (1985). The Youth Cohort and Indonesian History. Tahun Ke XIII (1): 1-13.

Lutz, W. (1984). Die Entwicklung paritätsspezifischer Fruchtbarkeitskontrolle. Modifikation und Applikation des 'Index of Family Limitation'. Zeitschrift für Bevölkerungswissenschaft (Wiesbaden, FRG) 10: 4 (449-462).

Lutz, W.; and Yashin, A. (1987). Comparative Anatomy of Fertility Trends: The Aging of the Baby Boom. WP-87-12. Laxenburg, Austria: International Institute for Applied Systems Analysis.

United Nations. (1985). World Population Prospects. Estimates and Projections as Assessed in 1982. New York: United Nations. 